\title{
Performance of the audio signals transmission over wireless networks with the channel interleaving considerations
}

\author{
Mohsen Ahmed Mahmoud Mohamed El-Bendary ${ }^{*}$, Atef E Abou-El-azm², Nawal A El-Fishawy ${ }^{2}$, Farid Shawki \\ Fathi E Abd-EISamie ${ }^{2}$, Mostafa Ali Refai El-Tokhy ${ }^{1}$ and Hassan B Kazemian ${ }^{3}$
}

\begin{abstract}
This article studies a vital issue in wireless communications, which is the transmission of audio signals over wireless networks. It presents a novel interleaver scheme for protection against error bursts and reduction the packet loss of the audio signals. The proposed technique in the article is the chaotic interleaver; it is based on chaotic Baker map. It is used as a randomizing data tool to improve the quality of the audio over the mobile communications channels. A comparison study between the proposed chaotic interleaving scheme and the traditional block and convolutional interleaving schemes for audio transmission over uncorrelated and correlated fading channels is presented. The simulation results show the superiority of the proposed chaotic interleaving scheme over the traditional schemes. The simulation results also reveal that the proposed chaotic interleaver improves the quality of the received audio signal. It improves the amount of the throughput over the wireless link through the packet loss reduction.
\end{abstract}

Keywords: wireless networks, Bluetooth, fading channels, interleaving techniques, mobility.

\section{Introduction}

With increasing utilization of wireless devices, especially Bluetooth devices, there are two important factors for all wireless systems power efficiency and efficient throughput. Bluetooth is designed to transfer data using ACL packets and SCO packets for transferring audio streams $[1,2]$.

Bluetooth uses $64 \mathrm{kbps} \log$ PCM voice coding with either A-law or $\mu$-law compression, it is the simplest. It uses an 8-bit logarithmic scale. Although it is simple to implement and it is useful in small applications. The log PCM is less robust than the continuous variable slope delta. It is a voice coding method, and is a delta modulation with variable step size. It is good noise immunity, where the damaged packets are discarded without impacting on sound quality [3-5]. In this study, the first voice coding log PCM is considered, for simplicity of the simulations.

\footnotetext{
* Correspondence: mohsenbendary@yahoo.com

'Department of Communications Technology, Faculty of Industrial

Education, Helwan University, Helwan, Egypt

Full list of author information is available at the end of the article
}

There are variety of methods exists for optimizing the transmission of audio data, depending on the properties of the underlying network. In this article, the fixed and mobile Bluetooth networks are assumed to have bursty loss. This study is focused on the interleaving techniques to reduce the burst error effects on the audio signals through distributing the burst errors through a set of audio samples. Audio signals are transmitted as packets in many Bluetooth applications. A packet is considered lost when it is corrupted to the point that it cannot be used. When a packet is lost, a large block of the digital bit stream is missing. The article proposed using effective and powerful interleaver based on the chaotic Baker map. The proposed chaotic interleaver reduces the number of lost packets as shown in the results. So, the packet loss of the audio signal is decreased with the proposed scenarios. Also, over the communications link which permits retransmission the corrupted packets, using the proposed technique reduces the number of retransmission requirement [6-8].

The rest of the article is organized as follows. In Section 2, Bluetooth links are discussed. In Section 3, the

\section{Springer}


proposed modifications are presented. In Section 4, the simulation assumptions are given. The simulation results are introduced in Section 5. Finally, the article is concluded in Section 6.

\section{SCO, eSCO, and ACL links}

Bluetooth supports both synchronous services such as voice traffic and asynchronous services such as bursty data traffic. The specifications define two different physical link types.

The SCO link is a symmetric, point-to-point link between the master and a single slave in the piconet. The SCO link is typically used to support time-bounded information like voice. The master can support up to three SCO links to the same slave or to different slaves. On the SCO links, the packets used include a CRC and are never retransmitted. The SCO packets have been designed to support $64 \mathrm{kbps}$ speech. There are three pure $\mathrm{SCO}$ packets, namely, $\mathrm{HV}_{1}, \mathrm{HV}_{2}, \mathrm{HV}_{3}$, and one hybrid SCO (DV) packet $[9,10]$. Also, the enhanced SCO (eSCO) link permits retransmitting the dropped voice packets. The packets of this link are $\mathrm{EV}_{3}, \mathrm{EV}_{4}$, and $\mathrm{EV}_{5}$ Also, the extended data rate (EDR) are eSCO, $2 \mathrm{EV}_{3}$, $2 \mathrm{EV}_{4}, 2 \mathrm{EV}_{5}, 3 \mathrm{EV}_{3}, 3 \mathrm{EV}_{4}$, and $3 \mathrm{EV}_{5}$ packets [11].

The ACL link provides a packet-switched connection between the master and all active slaves in the piconet. A slave can send an ACL packet if it has been addressed by the master in the previous slot. The ACL packets can be retransmitted. Only a single ACL link can exist between a master and a slave. There are encoded ACL packets such as $\mathrm{DM}_{1}, \mathrm{DM}_{3}$, and $\mathrm{DM}_{5}$, which are protected with a rate of $2 / 3 \mathrm{FEC}$. Also, there are uncoded ACL packets such as $\mathrm{DH}_{1}, \mathrm{DH}_{2}$, and $\mathrm{DH}_{5}$, which are not protected. These ACL are called classic ACL packets. In the recent Bluetooth versions, there are other packets that are specified such as $2 \mathrm{DH}_{1}, 2 \mathrm{DH}_{3}$, and $2 \mathrm{DH}_{5}$ or $3 \mathrm{DH}_{1}, 3 \mathrm{DH}_{3}$, and $3 \mathrm{DH}_{5}$, these packets are called EDR packets [12].

The simulations of this article concentrate on the ACL packets and EDR eSCO packets through many scenarios. The proposed technique improves the quality of the received audio signals and reduces the dropped packets over the bursty channel.

\section{Proposed modifications}

In this article, two audio files are used, file- 1 which meets the specification audio transmission over Bluetooth network. The second audio file-2 has different properties as shown in the simulation assumption section.

First, the size of audio file- 1 is 32 kbytes. This file will be segmented to small packets. There are many classic $\left(\mathrm{DH}_{1}\right)$ and EDR $\left(2 \mathrm{DH}_{1} \& 2 \mathrm{DM}_{1}\right)$ packets used for transferring audio files. For example, in the $\mathrm{DH}_{1}$ packets, each one of these packets contains 30 bytes. The duration of this file is $4 \mathrm{~s}$.

Number of packets $($ file- 1$)=32$ kbytes $/ 30$ bytes $\approx$ 1066 packets.

Number of audio portions (file- 1$)=4 \mathrm{~s} / 3.75 \mathrm{~ms} \approx$ 1066 portion.

Second, the size of audio file- 2 is 92 kbytes. This file will be segmented to small packets. Each one of these packets contains 30 bytes. The duration of DT audio file is $8 \mathrm{~s}$.

Number of packets $($ file- 2$)=92$ kbytes $/ 30$ bytes $\approx$ 3066 packets.

Number of audio portions (file- 2$)=8 \mathrm{~s} / 3.75 \mathrm{~ms} \approx$ 2133 portion.

As shown, audio file-1 matches Bluetooth specification in its properties. But, the second audio file- 2 does not meet Bluetooth specification. It is used with the long packets simulations.

In the simulation, different interleaving techniques are applied on the audio signal before transmission process. The two traditional types, bit-level interleaver and the convolutional interleaver, are used. Figure 1 shows the method of data reading in case of bit-level interleaver.

The second type is the convolutional interleaver that are introduced as no block deterministic interleavers that were investigated in some communication systems due to applying less memories in their structures compared with the block interleavers [13]. Convolutional interleavers are constructed by $\mathrm{T}$ parallel lines; each line has different number of memories from other line. The construction of convolutional interleaver is shown in Figure 2. This figure illustrates the convolutional interleaver with period $T=4$ and space value $M=1$ based on arithmetic sequence, the overall number of memories (delay) for the interleaver $(T, M)$ is given in Equation 1 [13]

$$
\begin{aligned}
S & =\sum_{i=1}^{T} s_{i}=M+2 M+\cdots+(T-1) M \\
& =\frac{T(T-1) M}{2}=6(\text { The simulation case } M=1, T=4)
\end{aligned}
$$

There is the last one of the proposed scenarios, which is the chaotic randomizing. It is performed using the chaotic Baker map. The Baker map is a chaotic map that generates a permuted version of a square matrix. In its discretized form, the Baker map is an efficient tool to randomize a square matrix of data. The discretized map can be represented for an $M \times M$ matrix as follows [14-21] 


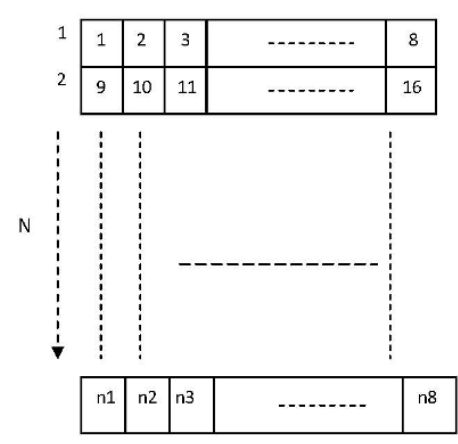

(a)

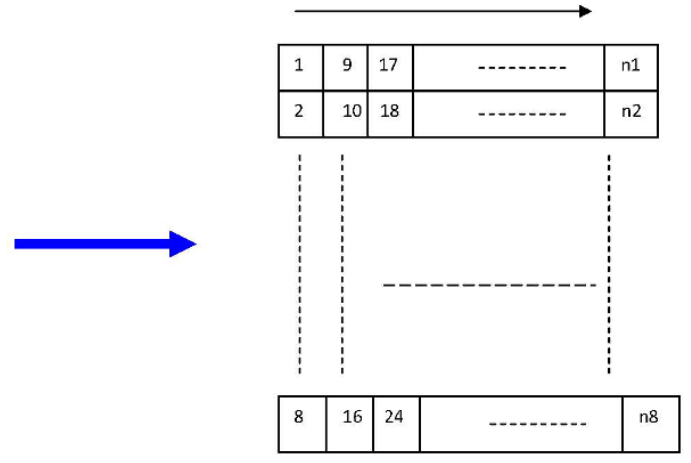

(b)

Figure 1 Bit-level interleaver of audio file after transforming to binary data. (a) Audio file in binary data form. (b) Audio file after bit-level interleaving.

$$
B(r, s)=\left[\frac{M}{n_{i}}\left(r-M_{i}\right)+s \bmod \left(\frac{M}{n_{i}}\right), \frac{n_{i}}{M}\left(s-s \bmod \left(\frac{M}{n_{i}}\right)\right)+M_{i}\right]
$$

where $B(r, s)$ are the new indices of the data item at $(r, s), M_{i} \leq r<M_{i}+n_{i}, 0<s<M$ and $M_{i}=n_{1}+n_{2}+\ldots$ $+n_{i}$.

In steps, the chaotic permutation is performed as follows:

1. An $M \times M$ square matrix is divided into $k$ rectangles of width $n_{i}$ and number of elements $M$.

2. The elements in each rectangle are rearranged to a row in the permuted rectangle. Rectangles are taken from right to left beginning with upper rectangles then lower ones. Inside each rectangle, the scan begins from the bottom left corner toward upper elements.

Figure 3 shows an example of the chaotic encryption of an $8 \times 8$ square matrix. The secret key is $S_{\text {key }}=\left(n_{1}\right.$, $\left.n_{2}, n_{3}\right)=(2,4,2)$.

This technique is employed in the simulation as a data randomizing tool. It is employed in two forms; it is applied on the audio file to randomize the whole audio file. Also, it is applied on the packet-by-packet basis for randomize the encoded packets. The simulation results reveal that the proposed technique improves the quality of the received audio signals.

\section{Simulation assumptions}

In this section, the simulation environment used for carrying out the computer simulation experiments is described. An important assumption used in the simulation is that a packet is discarded if there is an error in the access code, The Header, or Payload field, was not corrected using the error correction scheme. This is a realistic assumption to simulate the real Bluetooth systems' operation [22]. This assumption is employed to measure the number of corrupted packets, but the received packets are recollected after the decoding process for reconstruct the received audio signal.

In the simulation, $\mathrm{HV}_{3}$ packet is replaced by $\mathrm{DH}_{1}$ (ACL packet). The length of $\mathrm{DH}_{1}$ uncoded packet is 240 bits. There are two types of audio files used in the

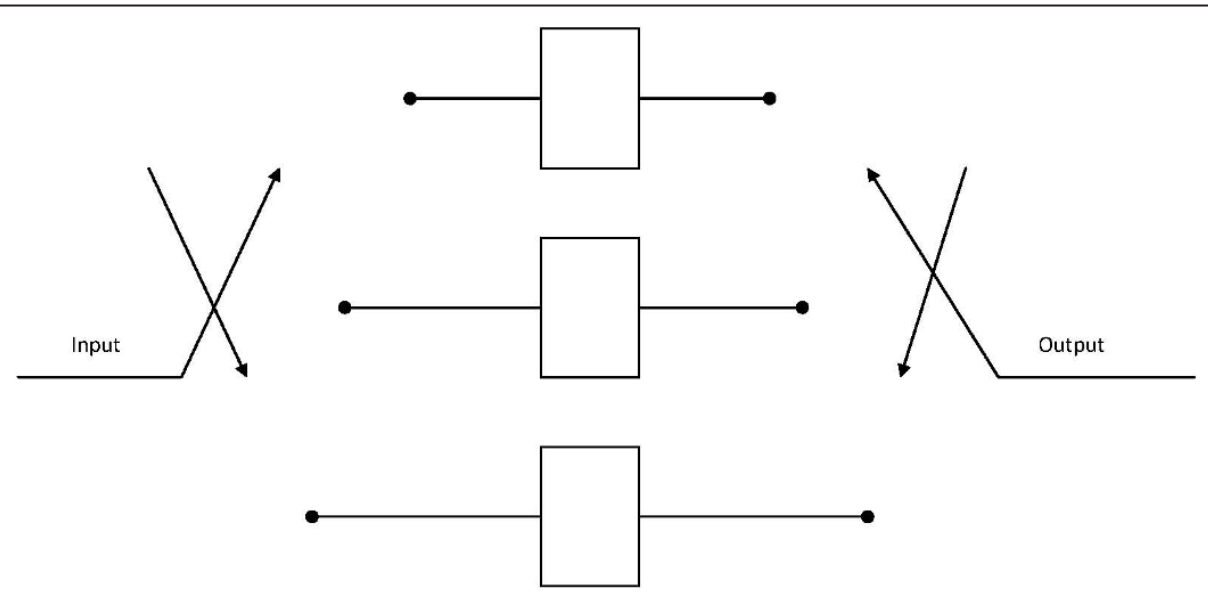

Figure 2 Convolutional interleaver structures. 


\begin{tabular}{|c|c|c|c|c|c|c|c|}
\hline$S_{1}$ & $s_{2}$ & $S_{3}$ & $S_{4}$ & $s_{5}$ & $S_{6}$ & $S_{7}$ & $S_{8}$ \\
\hline$S_{9}$ & $s_{10}$ & $s_{11}$ & $s_{12}$ & $s_{13}$ & $S_{14}$ & $s_{15}$ & $S_{16}$ \\
\hline$s_{17}$ & $S_{18}$ & $s_{19}$ & $s_{20}$ & $s_{21}$ & $s_{22}$ & $s_{23}$ & $S_{24}$ \\
\hline$s_{25}$ & $s_{26}$ & $S_{27}$ & $S_{28}$ & $s_{29}$ & $s_{30}$ & $s_{31}$ & $S_{32}$ \\
\hline$S_{33}$ & $S_{34}$ & $s_{35}$ & $s_{36}$ & $S_{37}$ & $s_{38}$ & $S_{39}$ & $S_{40}$ \\
\hline$S_{41}$ & $S_{42}$ & $S_{43}$ & $S_{44}$ & $S_{45}$ & $S_{46}$ & $S_{47}$ & $S_{48}$ \\
\hline$S_{49}$ & $S_{50}$ & $S_{51}$ & $S_{52}$ & $S_{53}$ & $S_{54}$ & $S_{55}$ & $S_{56}$ \\
\hline$S_{57}$ & $S_{58}$ & $S_{59}$ & $S_{60}$ & $s_{61}$ & $s_{32}$ & $s_{63}$ & $S_{64}$ \\
\hline
\end{tabular}

Output of PM

(a)

\begin{tabular}{|llllllll|}
\hline$s_{31}$ & $s_{23}$ & $s_{15}$ & $s_{7}$ & $s_{32}$ & $s_{24}$ & $s_{16}$ & $s_{8}$ \\
\hline$s_{63}$ & $s_{55}$ & $s_{47}$ & $s_{39}$ & $s_{64}$ & $s_{56}$ & $s_{48}$ & $s_{40}$ \\
\hline$s_{11}$ & $s_{3}$ & $s_{12}$ & $s_{4}$ & $s_{13}$ & $s_{5}$ & $s_{14}$ & $s_{6}$ \\
\hline$s_{27}$ & $s_{19}$ & $s_{28}$ & $s_{20}$ & $s_{29}$ & $s_{21}$ & $s_{30}$ & $s_{22}$ \\
\hline$s_{43}$ & $s_{35}$ & $s_{44}$ & $s_{36}$ & $s_{45}$ & $s_{37}$ & $s_{46}$ & $s_{38}$ \\
\hline$s_{59}$ & $s_{51}$ & $s_{60}$ & $s_{52}$ & $s_{61}$ & $s_{53}$ & $s_{32}$ & $s_{54}$ \\
\hline$s_{25}$ & $s_{17}$ & $s_{9}$ & $s_{1}$ & $s_{26}$ & $s_{18}$ & $s_{10}$ & $s_{2}$ \\
\hline$s_{57}$ & $s_{49}$ & $s_{41}$ & $s_{33}$ & $s_{58}$ & $s_{50}$ & $s_{42}$ & $s_{34}$ \\
\hline
\end{tabular}

Output of CMR

(b)

Figure $\mathbf{3}$ Chaotic encryption of an $\mathbf{8} \times \mathbf{8}$ matrix. (a) Original square matrix. (b) Chaotic encrypted matrix.

simulation: the audio file-1 (32 kbytes). Its characteristics are bit rate $64 \mathrm{kbps}$, audio sample size 8 bit, channel 1 mono, audio sample rate $8 \mathrm{kHz}$, and audio format PCM; and the audiofile-2 (92 kbytes), whose file characteristics are as follows: bit rate $88 \mathrm{kbps}$, audio sample size 8 bit, channel 1 mono, audio sample rate $11 \mathrm{kHz}$, and audio format PCM. Tables 1 and 2 show the properties of the audio files [23,24].

In the simulation, there are many different packet formats employed for audio transmission, and. also a blockfading channel is assumed. It is a slow and frequency nonselective channel, where symbols in a block undergo a constant fading effect, meaning that the Doppler spread equals zero $\left(F_{\mathrm{d}}=0\right)$. Also, the Jakes' model is utilized for simulating the correlated Rayleigh fading channel. The mobile Bluetooth device velocity is up to $20 \mathrm{mile} / \mathrm{h}$, and the carrier frequency is $2.481 \mathrm{GHz}$. The phase difference between the paths is given from Equation 2. The Doppler spread is expressed in Equation 3 [25].

Table 1 Simulation audio signal (file-2) parameters

\begin{tabular}{ll}
\hline Parameter & Description \\
\hline Bit rate & $88 \mathrm{kbps}$ \\
Audio sample size & $8 \mathrm{bit}$ \\
Channel & 1 (mono) \\
Audio sample rate & $11 \mathrm{kHz}$ \\
Audio format & $\mathrm{PCM}$ \\
File size & $92 \mathrm{kbytes}$ \\
Duration & $8 \mathrm{~s}$ \\
\hline
\end{tabular}

$$
\begin{aligned}
& \Delta \phi=\frac{2 \pi \Delta l}{\lambda}=\frac{2 \pi v_{c} \Delta t}{\lambda} \cos \theta \\
& F_{d}=\frac{1}{2 \pi} \cdot \frac{\Delta \phi}{\Delta t}=\frac{v_{c}}{\lambda} \cdot \cos \theta
\end{aligned}
$$

The obtained binary data are used to build the audio file again. The waveform of received audio signal is compared to original waveform of transmitted signal to evaluate the effects of the proposed modifications. In this study, the audio signal is transmitted and interleaved using the bit-level interleaving and the convolutional interleaving over the fading channels. Figures 4 and 5 show the original waveform of audio files 12 , respectively. MATLAB was used for carrying out the simulations of different scenarios. The simulation results have been acquired by the transmission of audio files over different SNR values.

Table 2 Simulation audio signal (file-1) parameters

\begin{tabular}{ll}
\hline Parameter & Description \\
\hline Bit rate & $64 \mathrm{kbps}$ \\
Audio sample size & $8 \mathrm{bit}$ \\
Channel & 1 (mono) \\
Audio sample rate & $8 \mathrm{kHz}$ \\
Audio format & $\mathrm{PCM}$ \\
File size & $32 \mathrm{kbytes}$ \\
Duration & $4 \mathrm{~s}$ \\
\hline
\end{tabular}




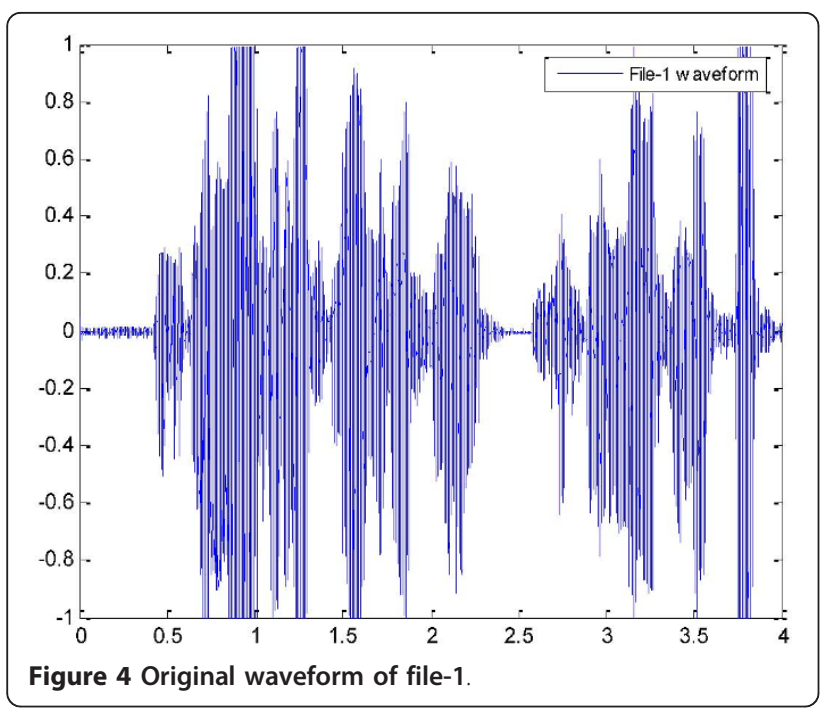

\section{Simulation results}

In this section, the performance of the proposed transmission audio signal through ACL link over correlated and uncorrelated Rayleigh fading channels is studied through simulation. For the comparison purpose, using different scenarios, non-interleaving, bit-level interleaver, convolutional interleaver, and the proposed chaotic randomizing techniques are also simulated. In the case of correlated Rayleigh fading channel, the Jakes' model is used in the simulation.

In this section, there are many simulation scenarios devoted for evaluating the proposed scenarios of the audio signal transmission.

\subsection{Short classic packets $\mathrm{DH}_{1}$}

This simulation studies the interleaving effects on the received waveform of audio signal over Rayleigh fading channel. The file-2 is transmitted over uncorrelated Rayleigh fading channel using the $\mathrm{DH}_{1}$ packets. Figure 6 illustrates the waveform of received audio signal at SNR $=25 \mathrm{~dB}$. It is clear that using the interleaving improves received waveform at the same SNR value.

As shown in Figure 6, the bit-level interleaving scenario performs better than other scenarios in this simulation over an uncorrelated Rayleigh fading channel.

The previous computer simulation is repeated over a correlated fading channel. This simulation is devoted to indicate the velocity $\left(V_{c}\right)$ of the mobile terminal on the waveform of the received audio signals. The simulation utilized the Jakes' model communication channel. The result of this simulation is given in Figure 7 , this figure shows the waveform of the received audio

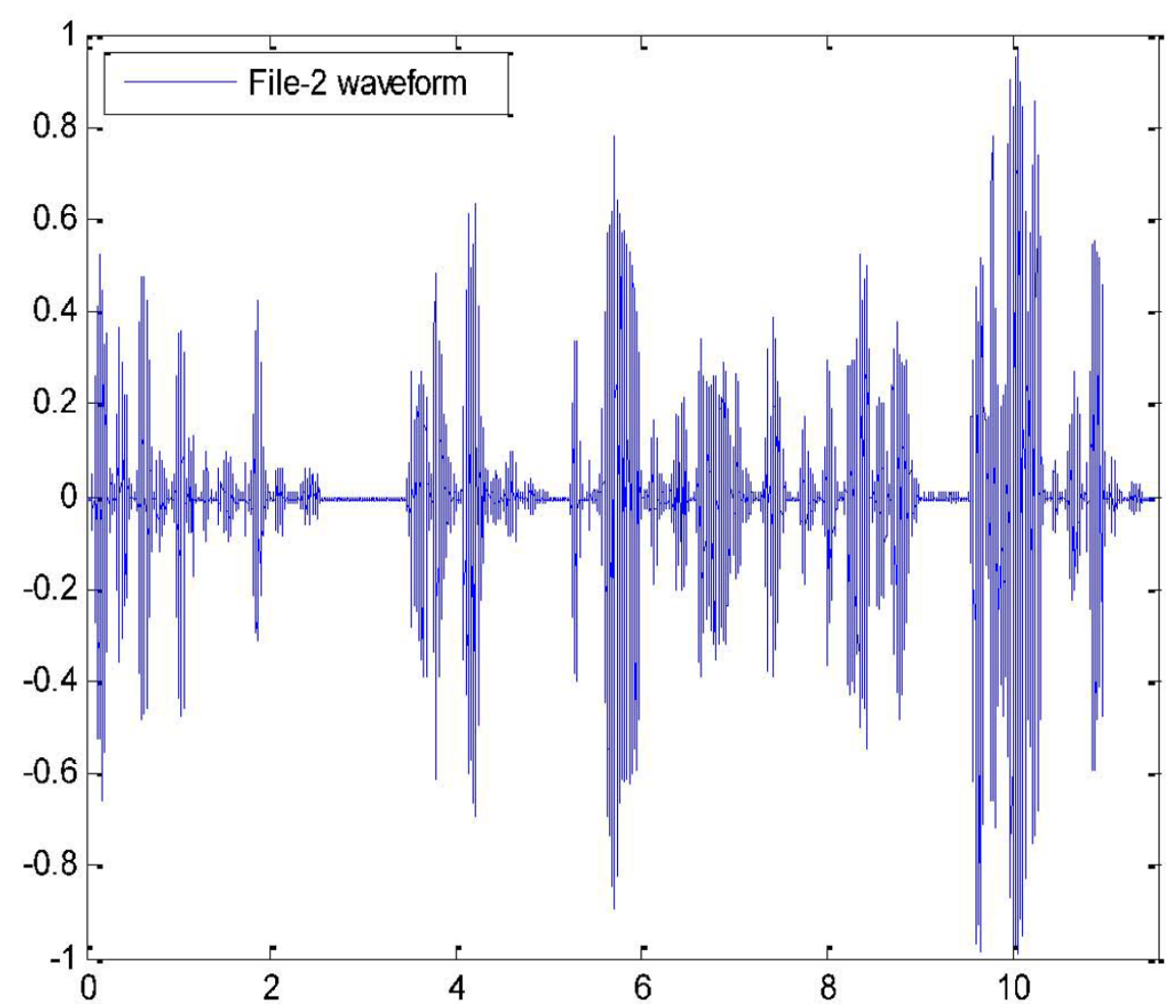

Figure 5 Original waveform of file-2. 


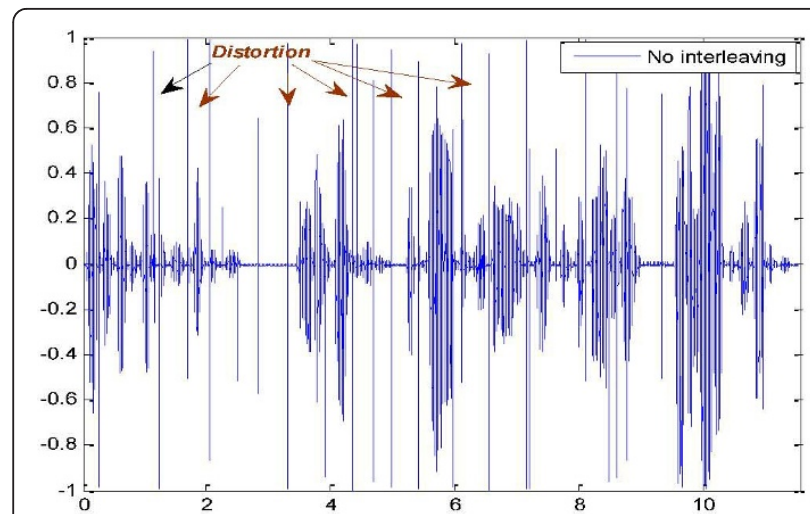

(c): No interleaving

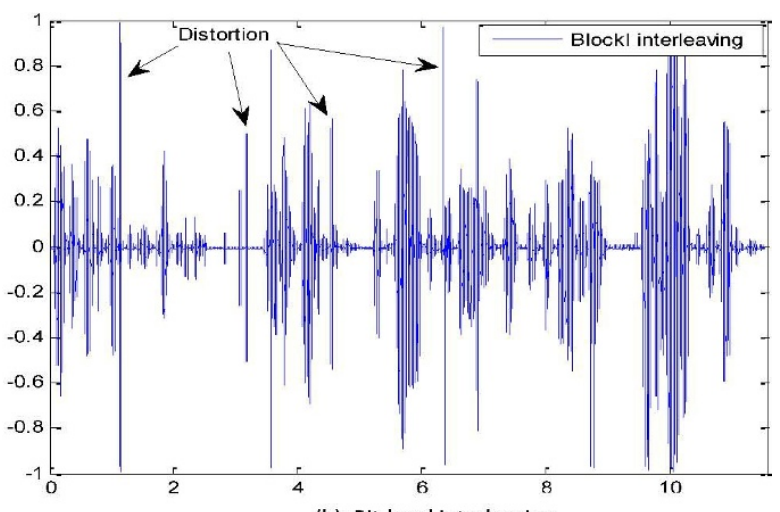

(b): Bit-level interleaving

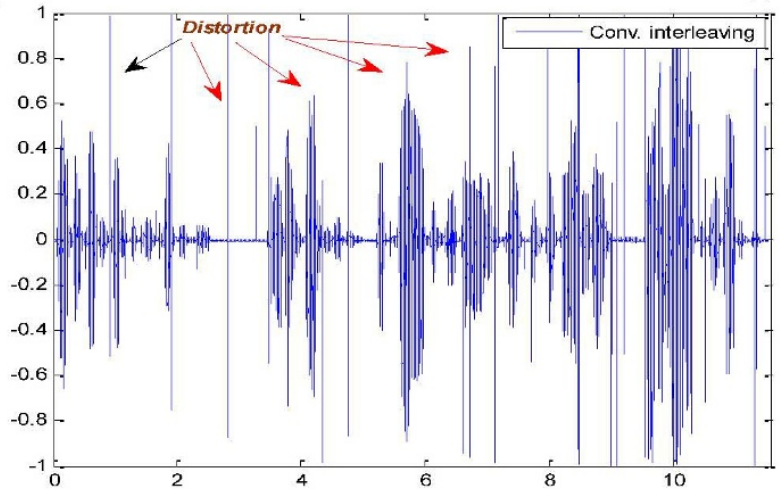

(c): Convolutional interleaving

Figure 6 Received audio signal of file-2 waveform over uncorrelated fading channel at SNR $=\mathbf{2 5} \mathrm{dB}$. (a) No interleaving. (b) Bit-level interleaving. (c) Convolutional interleaving.

signal with assuming the velocity of the mobility is 3 and $10 \mathrm{mile} / \mathrm{h}$.

The result of this simulation reveals that the mobility of the transmitter increases the distortion of the received audio signal. Also, the audio signal transmission needs strong interleaving technique to spread the errors and reduce the bad mobility effects.
In the following simulation, the interleaving effect on the received waveform of audio signal over uncorrelated fading channel is studied. The file- 1 is transmitted using the uncoded classic $\mathrm{DH}_{1}$ packets. Figure 8 illustrates the waveform of received audio signal at SNR $=20 \mathrm{~dB}$. It is clear that using the interleaving improves received waveform at the same SNR value. The audio file-1

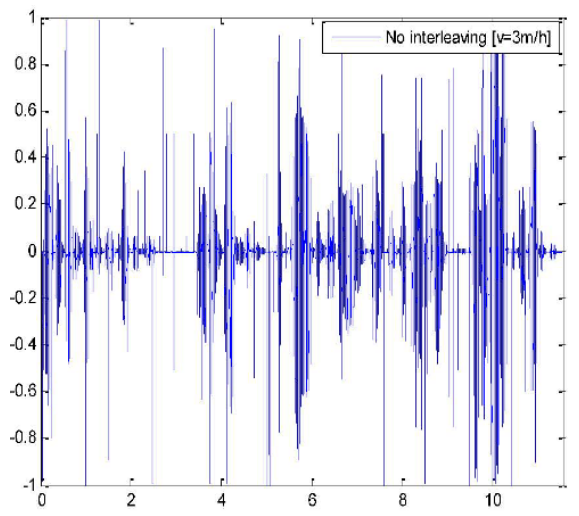

(a): $V_{c}=3 \mathrm{~m} / \mathrm{h}$

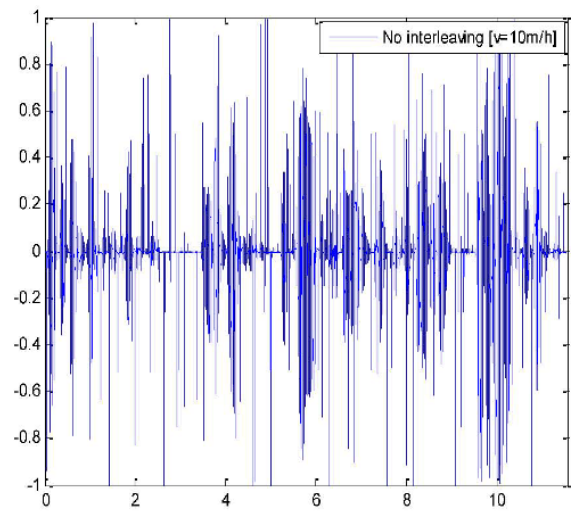

(b): $V_{c}=10 \mathrm{~m} / \mathrm{h}$

Figure 7 Received audio file-2 signal waveform over a correlated fading channel at SNR $=\mathbf{2 5} \mathbf{d B}$. (a) $V_{c}=3 \mathrm{mile} / \mathrm{h}$. (b) $V_{c}=10 \mathrm{mile} / \mathrm{h}$. 


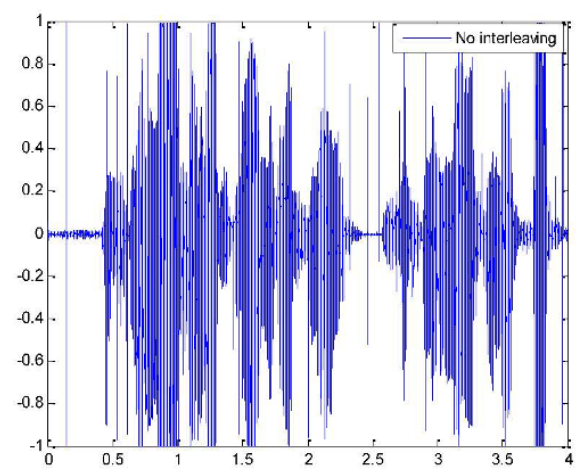

(a): No interleaving

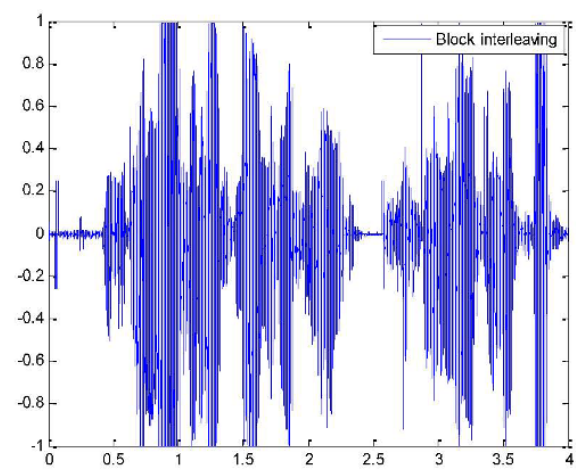

(b): Bit-level interleaving

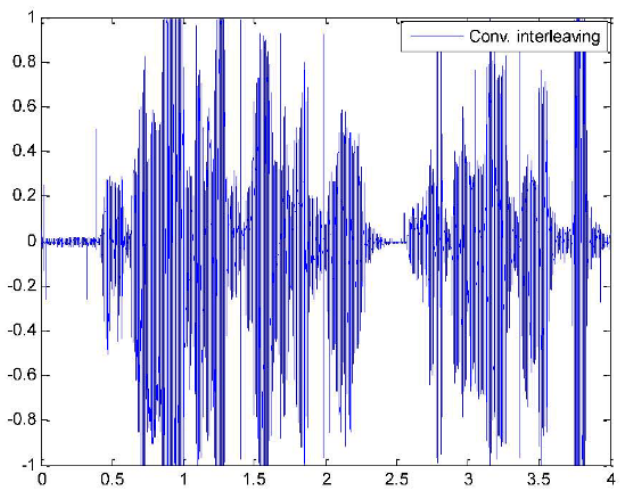

(c): Convolutional interleaving

Figure 8 Received audio signal of file-1 waveform over uncorrelated fading channel at SNR $=\mathbf{2 0}$ dB. (a) No interleaving. (b) Bit-level interleaving. (c) Convolutional interleaving.

characteristics match the Bluetooth specifications as mentioned previously. As shown in this simulation results, the waveforms of the received audio signals clear that the bit-level interleaver performs better than the convolutional interleaver. Figure 8 also reveals that the convolutional interleaver enhances the waveform of the received audio signal more than the no interleaving scenario.

In the last simulation of this section, the audio file-2 is transmitted over a correlated Rayleigh fading channel $\left[V_{c}=10 \mathrm{mile} / \mathrm{h}\right]$ using the $\mathrm{DH}_{1}$ packets. Figure 9 illustrates the waveform of received audio signal at SNR = $20 \mathrm{~dB}$. It is clear that the convolutional interleaver scenario performs better than other scenarios over a correlated fading channel.

In the previous simulation, the performance of the audio signals transmission is studied over uncorrelated and correlated fading channels with different mobility velocities. These simulation scenarios indicated that there are bad effects of the mobility on the received audio signal waveforms. Also, it reveals that the interleaving techniques improve the audio waveforms. In the following section, the simulation evaluates the proposed interleaving technique which is the chaotic randomizing technique, based on the chaotic Baker map.

\subsection{Randomizing technique}

In this section, the simulation results of the proposed technique are presented. The simulation senarios have been carried out for different types of Bluetooth packets; $2 \mathrm{DH}_{1}$ and $2 \mathrm{DM}_{1}$ with the different signal-to-noise ratios (SNRs). The peak SNR, the absolute number of lost frames (NLF), NLF percentage (NLF \%), bit error rate (BER), and the correlation coefficient $(\mathrm{Cr})$ are employed for measuring the correlation between the original and the received images; the mean square error (MSE) and the throughput $(T)$ are used for performance evaluation of the Bluetooth network in the different simulation scenarios [26]. The MSE is the cumulative squared error between the received audio signal and the original signal. The mathematical formula for MSE is given in Equation 4 [27].

$$
M S E=\frac{1}{M N} \sum_{y=1}^{M} \sum_{x=1}^{N}\left[I(x, y)-I^{\prime}(x, y)\right]^{2}
$$




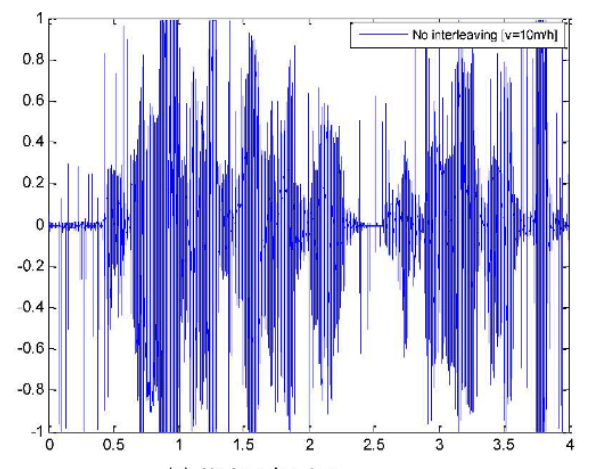

(a): No interleaving

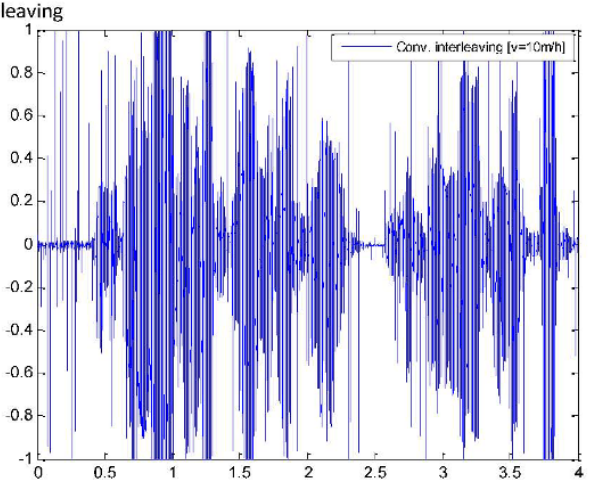

(c): Convolutional interleaving

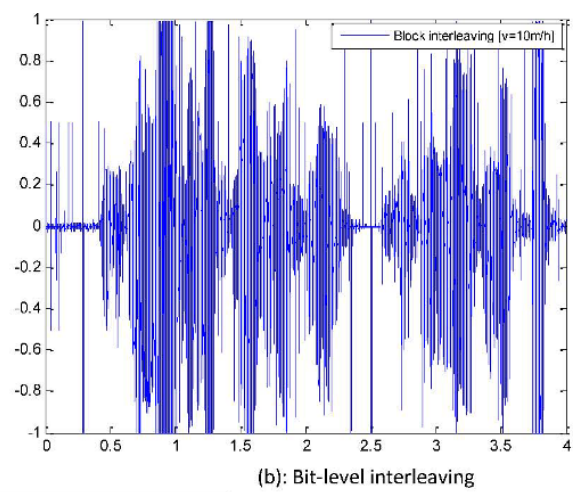

(b): Bit-level interleaving

Figure 9 Received audio signal of file-1 waveform over a correlated fading channel $\left(V_{c}=10 \mathrm{mile} / \mathrm{h}\right)$ at $\mathrm{SNR}=20 \mathrm{~dB}$. (a) No interleaving. (b) Bit-level interleaving. (c) Convolutional interleaving.

The throuput is defined as [28]

$$
T=\frac{P_{l}(1-P E R)}{(x+1) t}
$$

where $P_{l}$ is the payload length, PER is the packet error rate, $x$ is the number of time slots occupied by the Bluetooth packet, and $t$ is the duration of the Bluetooth time slots.

In the following, the EDR Bluetooth packets are used for transmitting audio signal over mobile Bluetooth network. The proposed Bluetooth terminal velocity $\left(V_{c}\right)$ is 10 and $3 \mathrm{mile} / \mathrm{h}$ and the frequency carrier is $2.46 \mathrm{GHz}$. As shown in the following results, with increasing the velocity of Bluetooth terminal, the performance is degraded and the effect of channel on the transmitted signal is increased. Figure 10a gives the frame error rate (FER) of standard $2 \mathrm{DH}_{1}$ and proposed $2 \mathrm{DM}_{1}$ packets which is used for transmitting the audio signal with many proposed cases at $V_{c}=3 \mathrm{mile} / \mathrm{h}$. Figure $10 \mathrm{~b}$ gives FER at $V_{c}=10 \mathrm{mile} / \mathrm{h}$. Figure 11 gives the comparison of NFL and FER with the velocity variations with the standard uncoded packets.

From the previous section, the following is concluded: Over mobile Bluetooth network, the quality of audio transmission is decreased with $V_{c}$ increasing. Traditional block interleaving of audio file is inefficient over mobile network. The proposed encoded EDR packets with block interleaving of encoded packet performs better than encoded packets $\left(2 \mathrm{DM}_{1}\right)$, which represents $2 \mathrm{EV}_{3}$ voice packets. The performance of standard packets $\left(2 \mathrm{DH}_{1}\right)$ is very bad compared with proposed cases.

Also in this section, the proposed different scenarios for studying the audio signal performance with the proposed randomize techniques are presented. The results of these scenarios are shown in Figure 12. The results of this simulation indicate the effects of the mobility on the audio signal. As shown in this figure in case of $V_{c}=$ $3 \mathrm{mile} / \mathrm{h}$, the NFL of the whole simulation scenarios are much closed but with $V_{c}=10 \mathrm{mile} / \mathrm{h}$ its performance became different.

As shown in the previous results, the randomize technique which is based on the chaotic Baker map concepts scenario performs better than other technique. From these results, the proposed chaotic interleaver packet by packet basis is presented as a novel efficient interleaver. The proposed technique is evaluated through two groups of simulations according to the type of packets which is employed for the proposed technique testing. These packets are the uncoded $2 \mathrm{DH}_{1}$ and encoded $2 \mathrm{DM}_{1}$ EDR packets. 


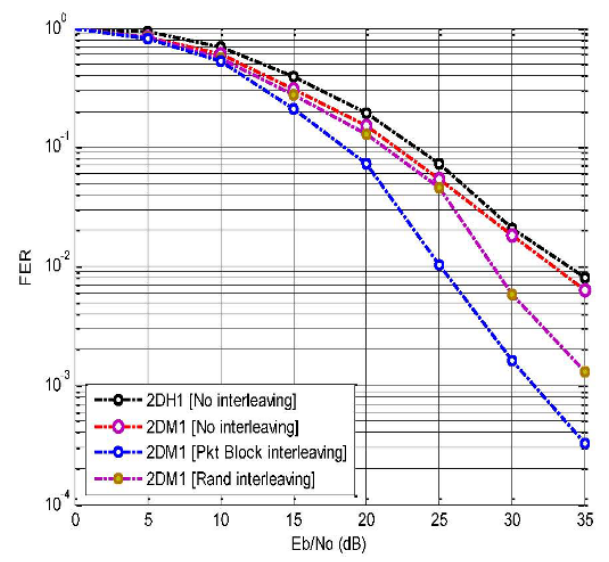

(a) $-V_{c}=3 \mathrm{~m} / \mathrm{h}$.

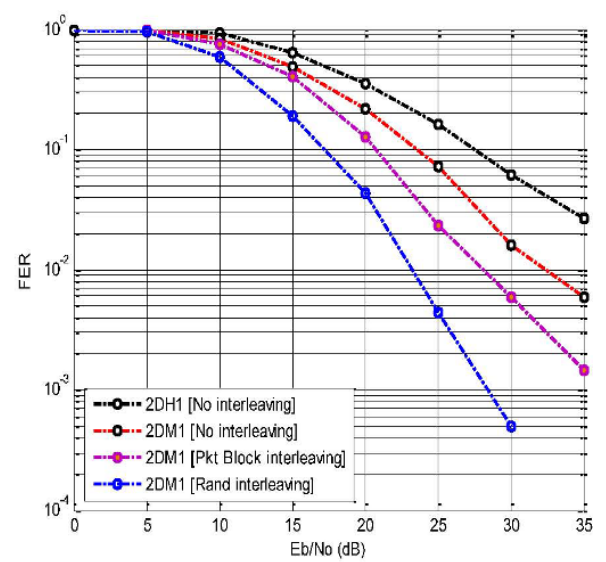

(b) $-V_{c}=10 \mathrm{~m} / \mathrm{h}$.

Figure 10 FER of audio signal versus SNR over correlated fading channel. (a) $V_{c}=3$ mile/h. (b) $V_{c}=10$ mile/h.

\subsection{The mobility effects on the audio transmission performance}

This section is devoted for studying the effects of the mobility of the wireless ad hoc network device $\left(V_{c}\right)$ on the transmitted packets and the received audio signals. In this computer simulation, the $v$ is 1 up to 20 miles/h. Figures 13, 14, and 15 show the NLF, Cr, and MSE variation with the channel SNR with the shortest EDR uncoded packets $2 \mathrm{DH}_{1}$, respecteively. It is clear that with increasing the $V_{c}$ of the terminal the NLF increased and the correlation between the original audio signal and the received signal is decreased. As shown in Figure 13, the MSE increased with the velocity increasing. Figure 16 gives the throughput variation with the different velocity of the mobility. So, these results indicate the mobility effects on the different metric of the perfromance evaluation.

The previous results reveal that it should be finding efficient technique for reducing the bad effect of the mobility on the audio signal transmission. In the following simulation scenarios, number of scenarios are proposed for this purpose. The proposed scenarios are applied on different packet lengths. These scenarios depend on that the interleaving technique is an efficient method for anti-fading, and is raised to solve serious long burst interference in some fading channels. The proposed scenarios are tested in two groups of the EDR packets with different velocities with employing the widely accepted Jakes' model to modelate the simulation environment. Figure 17 gives the waveforms

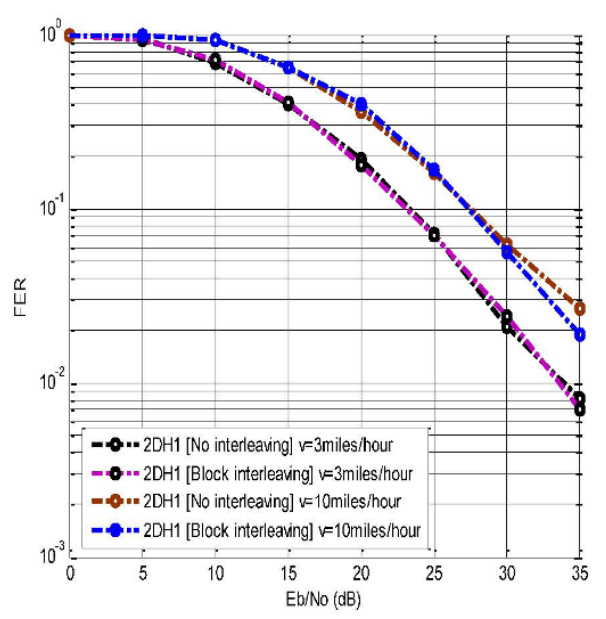

(a) - FER at $V_{c}=3 / 10 \mathrm{~m} / \mathrm{h}$

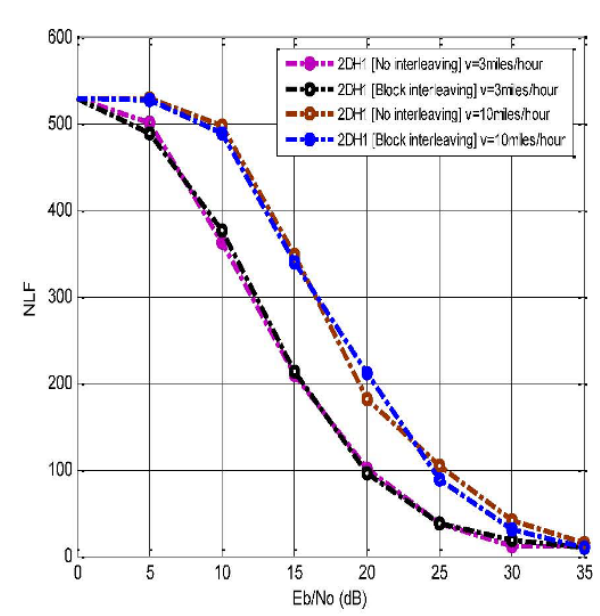

(b) - NLF at $V_{c}=3 / 10 \mathrm{~m} / \mathrm{h}$

Figure 11 FER and NFL of audio signal versus SNR over correlated fading channel. (a) FER at $V_{c}=3 / 10$ mile/h. (b) NLF at $V_{c}=3 / 10$ mile/ h. 


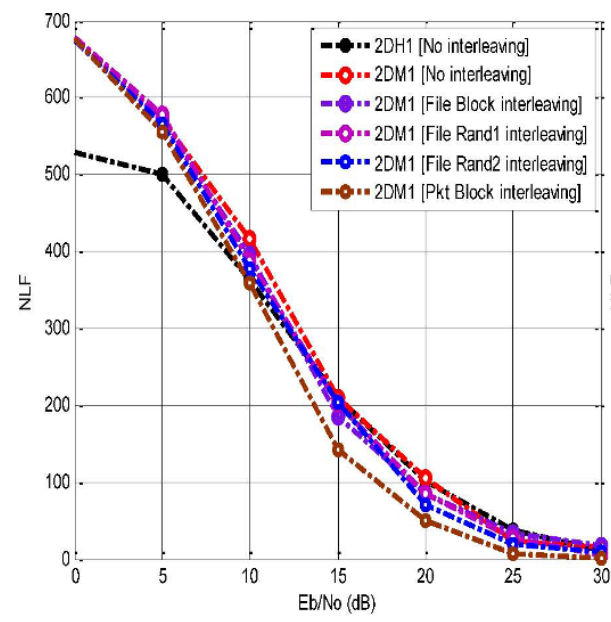

(a) $V c=3 \mathrm{~m} / \mathrm{h}$

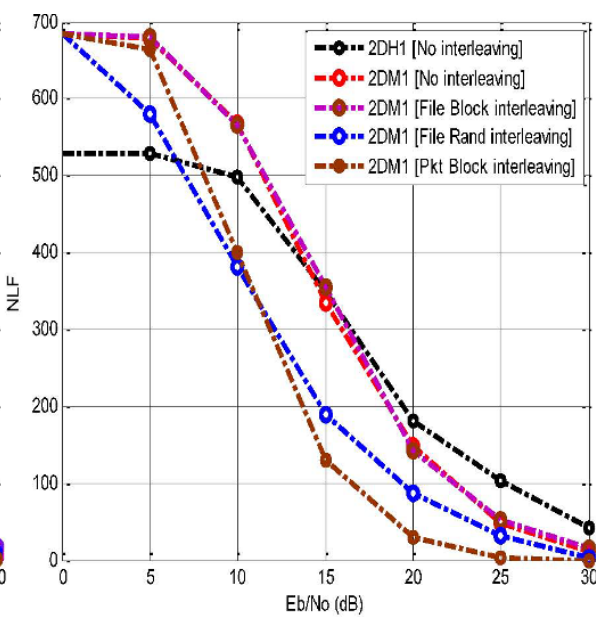

(b) $V c=10 \mathrm{~m} / \mathrm{h}$.

Figure $12 \mathrm{NFL}$ of audio signal versus $E_{b} / N_{o}$ over correlated fading channel. (a) $V_{c}=3 \mathrm{mile} / \mathrm{h}$. (b) $V_{c}=10 \mathrm{mile} / \mathrm{h}$.

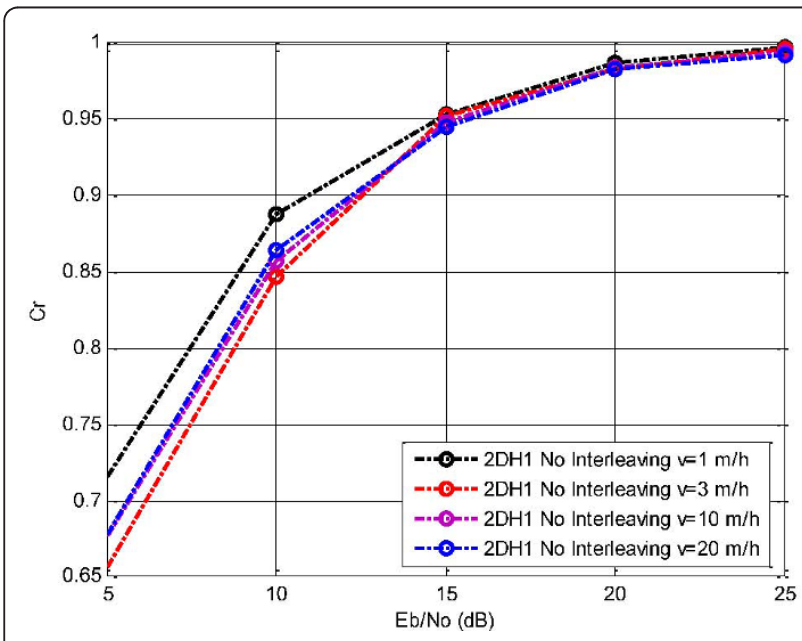

Figure $13 \mathrm{Cr}$ of audio signal vs. SNR for $2 \mathrm{DH}_{1}$ packets over correlated fading channel with $V_{c}=1$ up to $20 \mathrm{mile} / \mathrm{h}$.

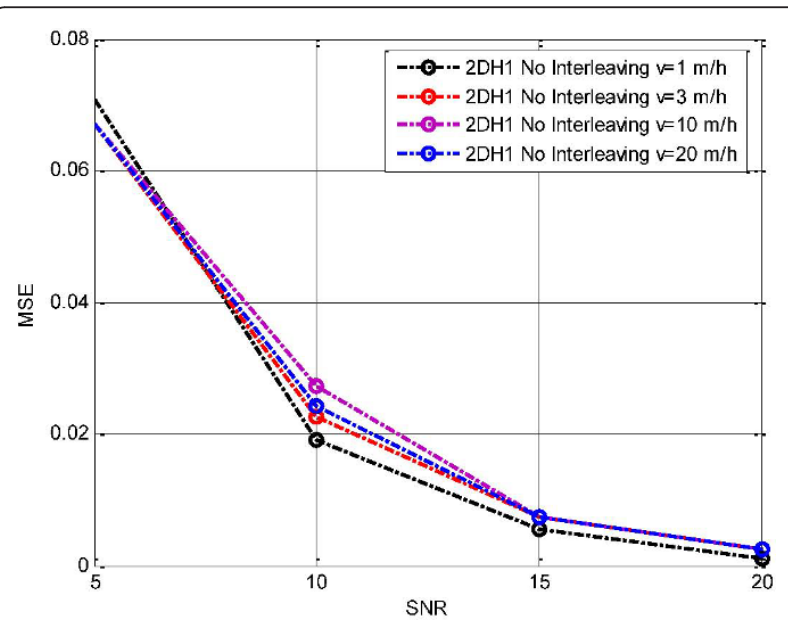

Figure 14 MSE of audio versus SNR for $2 \mathrm{DH}_{1}$ packets over correlated fading channel with different $V_{c}$.

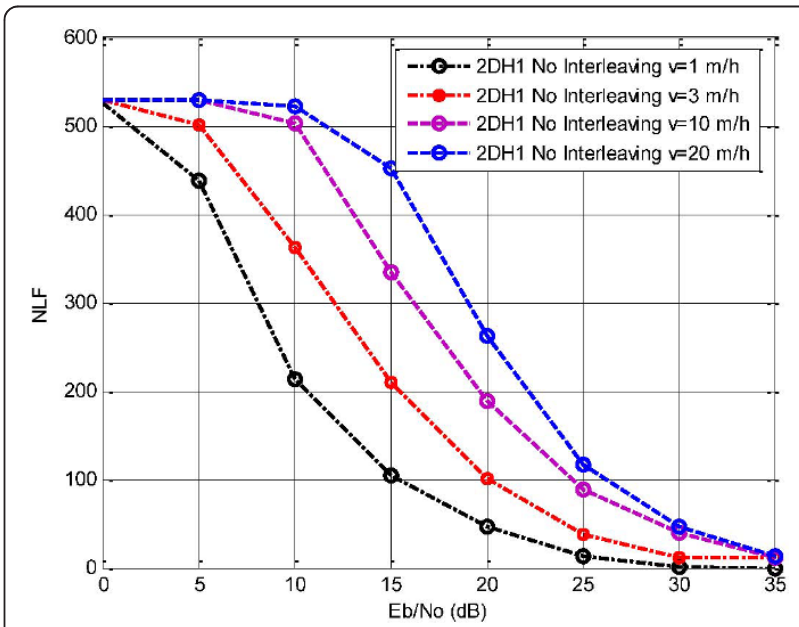

Figure 15 NLF of audio signal versus SNR over correlated fading channel with different $V_{c}$.

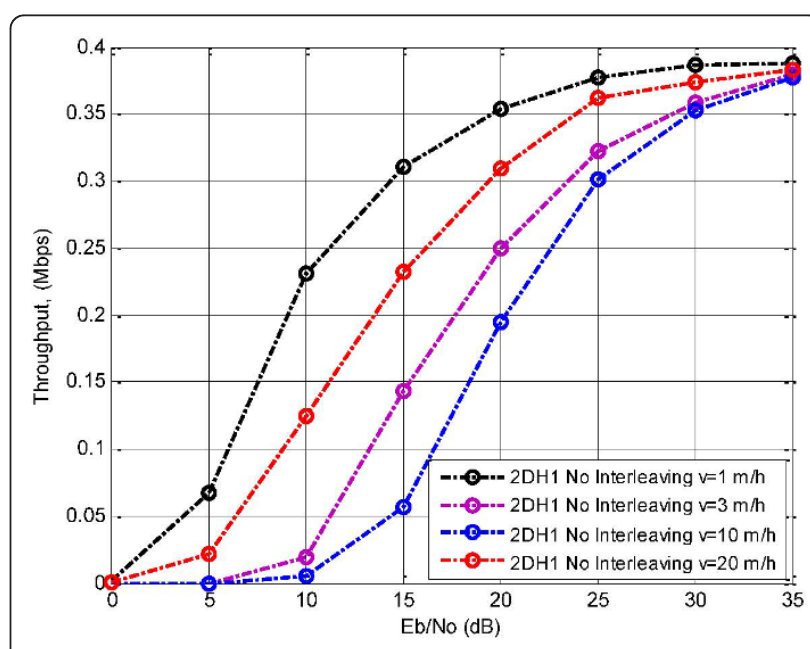

Figure 16 Throughput of audio signal versus SNR over correlated fading channel with different $V_{c}$. 

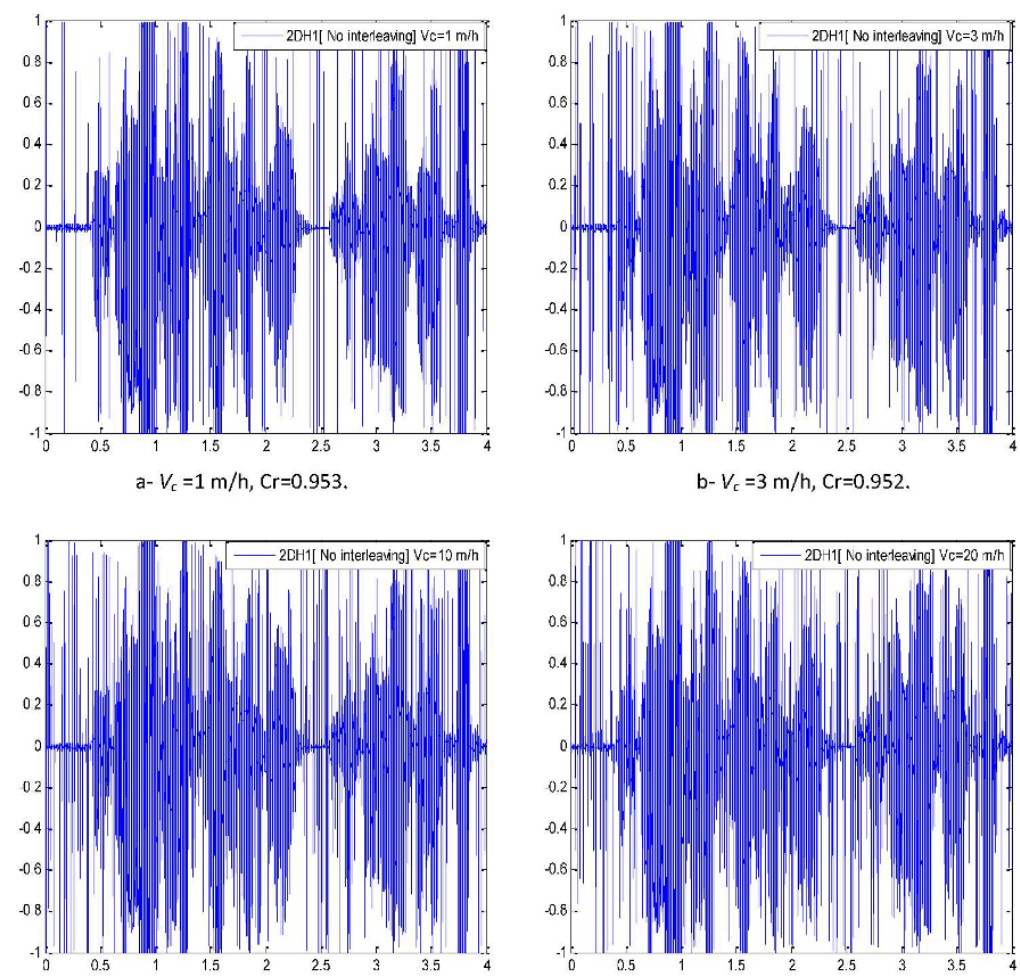

$\mathrm{c}-\mathrm{V}_{\mathrm{c}}=10 \mathrm{~m} / \mathrm{h}, \mathrm{Cr}=0.947$

d $-V_{c}=20 \mathrm{~m} / \mathrm{h}, \mathrm{Cr}=0.944$.

Figure 17 Audio signal transmission using $2 \mathrm{DH}_{1}$ packets over a correlated Rayleigh fading channel at $\mathrm{SNR}=15 \mathrm{~dB}$ with different $V_{c}$. (a) $V_{c}=1$ mile/h, $C r=0.953$. (b) $V_{c}=3$ mile $/ \mathrm{h}, C r=0.952$. (c) $V_{c}=10$ mile/h, $C r=0.947$. (d) $V_{c}=20 \mathrm{mile} / \mathrm{h}, \mathrm{Cr}=0.944$.

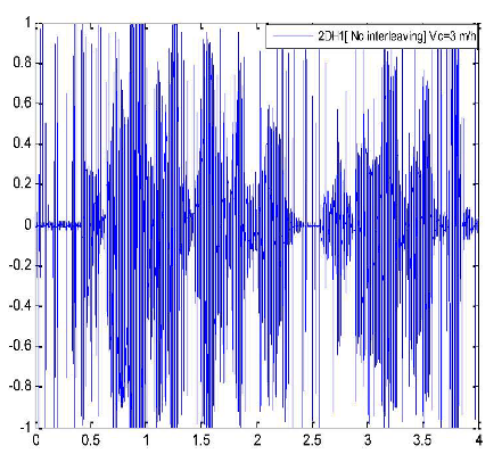

a- $2 \mathrm{DH}_{1}$ [No interleaving], $\mathrm{Cr}=0.953$.

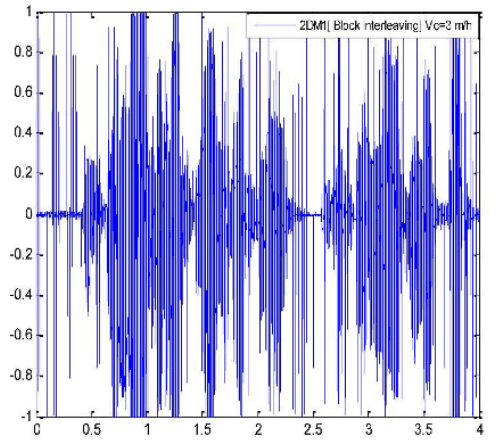

C- $2 \mathrm{DM}_{1}$ [Block interleaving], $\mathrm{Cr}=0.97$.

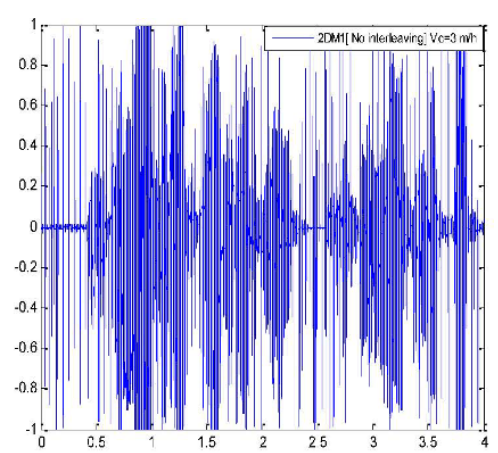

b- $2 \mathrm{DM}_{1}$ [No interleaving], $\mathrm{Cr}=0.957$.

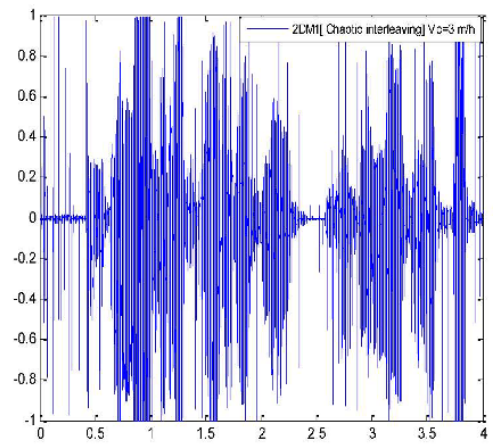

d- $2 \mathrm{DM}_{1}[$ Chaotic randomizing], $\mathrm{Cr}=0.98$

Figure 18 Audio signal transmission using $2 \mathrm{DH}_{1} \& 2 \mathrm{DM}_{1}$ packets over a correlated Rayleigh fading channel at $\mathrm{SNR}=15 \mathrm{~dB}$ with different scenarios $\left\{V_{c}=\mathbf{3}\right.$ mile/h). (a) $2 \mathrm{DH}_{1}$ (No interleaving), $\mathrm{Cr}=0.953$. (b) $2 \mathrm{DM}_{1}$ (No interleaving), $\mathrm{Cr}=0.957$. (c) 2DM 1 (Block interleaving), $\mathrm{Cr}=0.97$. (d) $2 \mathrm{DM}_{1}$ (Chaotic randomizing], $\mathrm{Cr}=0.98$. 
of the received audio signal with different $V_{c}$ of the mobility.

\subsection{Audio signal transmission using $2 \mathrm{DH}_{1}$ and $2 \mathrm{DM}_{1}$ packets}

This section is devoted to test the efficiency of audio transmission using the short uncoded $2 \mathrm{DH}_{1}$ and encoded $2 \mathrm{DM}_{1}$ EDR packets with the different scenarios. In the first computer simulation, the audio signal has been transmitted over a correlated fading channel with an SNR $=15 \mathrm{~dB}$. The results of this simulation are shown in Figure 18. From these results, it is clear that the effect of the proposed randomizing interleaving based on the chaotic Baker map is better than that of the other schemes. As shown in Figure 18, the waveform of the received audio signal is improved with the proposed scenarios. The proposed velocity of the mobility in this simulation is $V_{c}=3 \mathrm{mile} / \mathrm{h}$.

Figures 19 and 20 show the variation of the $\mathrm{Cr}$ and the MSE of the received audio signals with the channel SNR, respectively. These figures reveal that the proposed chaotic interleaver improves the quality of the received audio signal. It increases the correlation and decreases the error between the received and the original signals. Figure 21 indicates the effectiveness of the proposed scenarios on the error performance through the BER variation with the channel SNR. As shown in this figure, the error spreading capability of the proposed chaotic randomizing technique enhances the error performance over the mobile channel for the audio signal transmission. Figure 22 gives the NLF \% variation with the channel SNR. The effect of the velocity on the dropped packets is indicated in Figure 15 for the uncoded $2 \mathrm{DH}_{1}$ EDR packets, in this simulation the dropped packets are

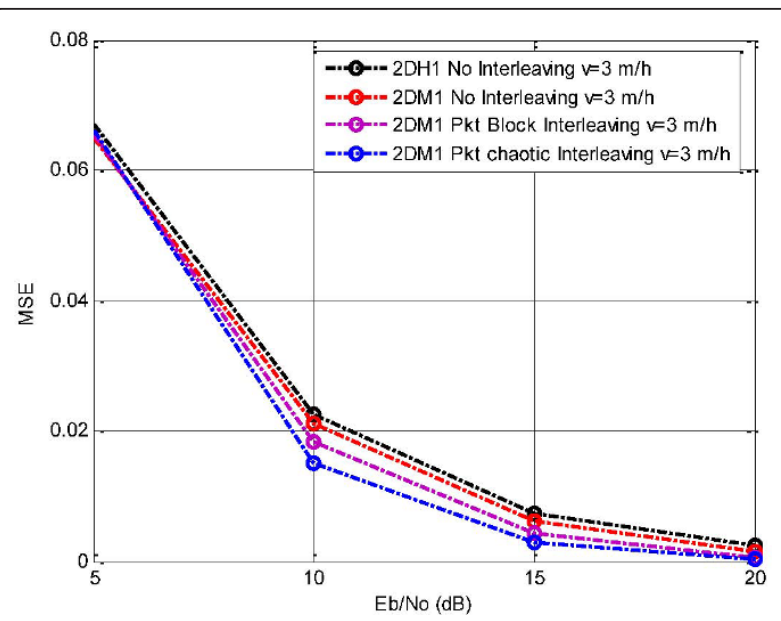

Figure 20 MSE versus $E_{b} / N_{o}$ for the audio signal transmission over a correlated Rayleigh fading channel using $2 \mathrm{DH}_{1} \& 2 \mathrm{DM}_{1}$ packets with different scenarios $\left\{V_{c}=3 \mathrm{mile} / \mathrm{h}\right\}$.

calculated as percentage where the audio file is segmented and transmitted through uncoded and encoded packets.

In the previous simulation, the mobility effect is studied on the audio signal transmission in a fixed and mobile communication channels in many of scenarios. Also, it evaluates the proposed chaotic interleaver on the whole audio file and packet-by-packet basis. The simulation results reveal that the ACL link improves the throughput of the audio signal. Also, the interleaving techniques enhance the received audio signals. The proposed data randomizing tool performs better than traditional interleavers over the mobile Bluetooth network. As shown in the results, the MSE and $\mathrm{Cr}$ of the received

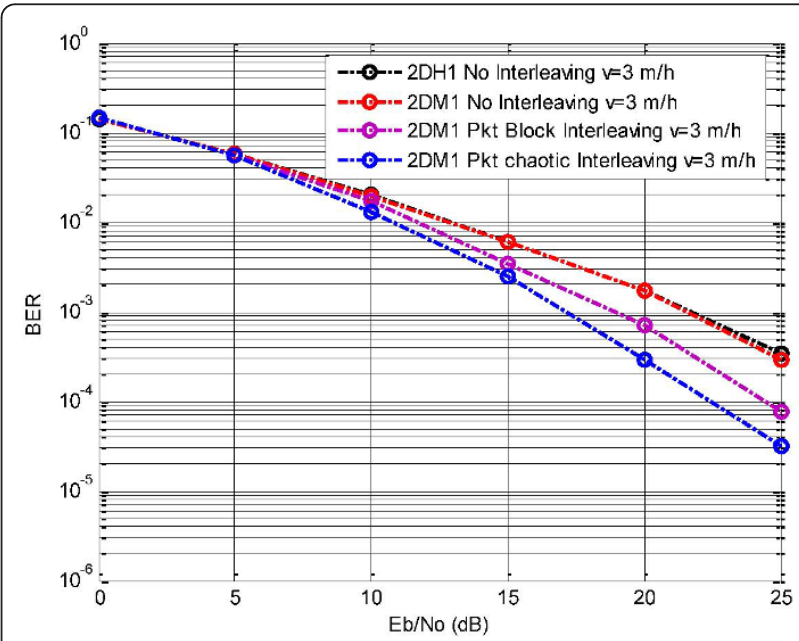

Figure $21 \mathrm{BER}$ versus $E_{b} / N_{o}$ for the audio signal transmission over a correlated Rayleigh fading channel using $2 \mathrm{DH}_{1} \& 2 \mathrm{DM}_{1}$ packets with different scenarios $\left\{V_{c}=3 \mathrm{mile} / \mathrm{h}\right\}$.
Figure $19 \mathrm{Cr}$ versus $E_{b} / N_{o}$ for the audio signal transmission over a correlated Rayleigh fading channel using $2 \mathrm{DH}_{1} \& 2 \mathrm{DM}_{1}$ packets with different scenarios $\left\{V_{c}=3 \mathrm{mile} / \mathrm{h}\right\}$. 


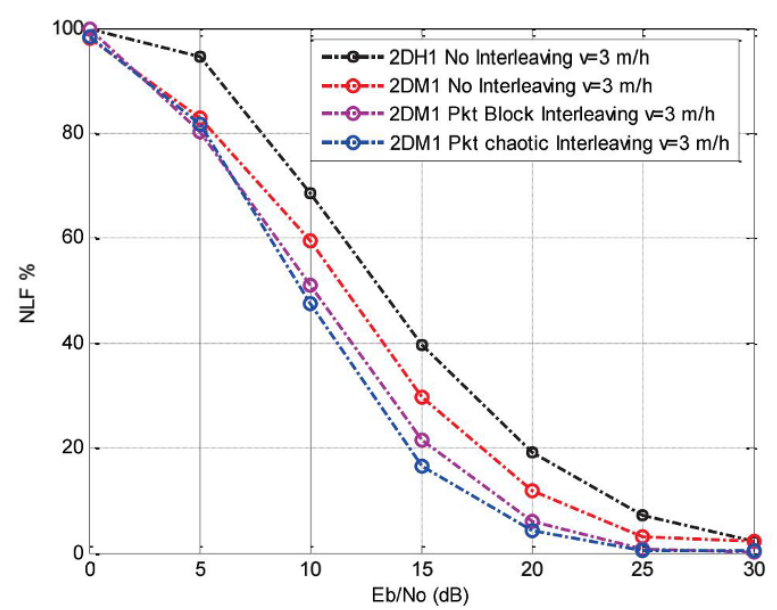

Figure $22 \mathrm{NLF} \%$ versus $E_{b} / N_{o}$ for the audio signal transmission over a correlated Rayleigh fading channel using $2 \mathrm{DH}_{1} \& 2 \mathrm{DM}_{1}$ packets with different scenarios $\left\{V_{c}=3 \mathrm{mile} / \mathrm{h}\right\}$.

audio signals are improved by applying the proposed scenario of the chaotic randomizing technique.

\section{Conclusions}

In this article, the transmission of voice using ACL link is discussed. In the simulation two different audio files and different interleaver types were used. The simulations were carried out over Rayleigh correlated and uncorrelated fading channels. The simulation results reveal that over uncorrelated fading channel the best choice is bit-level interleaver in case of the classic uncoded packets, whereas over correlated fading channel, the convolutional interleaver is efficient. Also, the effectiveness of the interleaving techniques is inefficient with audio file that has higher bit rate than $64 \mathrm{kbps}$. The ACL link is an efficient for carrying voice unless there is a need for high-quality voice. Using this link for carrying voice also leads to improving the throughput. ACL link is a suitable choice for carrying voice specially with using interleaving technique. The article proposes a novel data randomizing tool for enhance the quality of the audio signal transmission over ACL link. The proposed chaotic technique performs better than the traditional interleaver over the mobile channel. It can be then applied on the EV packets and on the mobile Ad hoc network. It reduces the packet loss of the transmitted audio file and also it is an efficient tool for decreasing the mobility bad effects on the transmitted audio signals.

\section{Author details}

${ }^{1}$ Department of Communications Technology, Faculty of Industrial Education, Helwan University, Helwan, Egypt ${ }^{2}$ Department of Electronics and Electrical Communications, Faculty of Electronic Engineering, Menoufia
University, Menouf 32952, Egypt ${ }^{3}$ Intelligent Systems Research Centre, Faculty of Computing, London Metropolitan University, London, UK

\section{Competing interests}

The authors declare that they have no competing interests.

Received: 27 October 2010 Accepted: 17 January 2012

Published: 17 January 2012

\section{References}

1. MAM Mohamed, A Abou El-Azm, N El-Fishwy, MAR El-Tokhy, FE Abd ElSamie, Optimization of bluetooth packet format for efficient performance. Prog Electromagn Res M. 1, 101-110 (2008)

2. IEEE 802.15.4 Wpan-Ir Task Group, http://www.ieee802.org/15/pub/TG4.html

3. J Kardach, Bluetooth architecture overview. Intel Technol J. Q2, 1-7 (2000)

4. IEEE 802.15 Wpan taskgroup 1 (tg), http://www.ieee802.org/15/pub/TG1. html

5. P Johansson, R Kapoor, M Kazantzidis, M Gerla, Bluetooth: an enabler for personal area networking. IEEE Netw. Mag (September/October, 28-37 2001)

6. IEEE 802.11, the working group setting the standards for wireless LANS, http://grouper.ieee.org/groups/802/11/

7. W Feng, A Nallanathan, HK Garg, Introducing packet segmentation for IEEE $802.11 \mathrm{~b}$ throughput enhancement in the presence of Bluetooth. in 59th Vehicular Technology Conference VTC, 2252-2256 (17-19 May 2004)

8. S Galli, D Famolari, T Kodama, Bluetooth: channel coding considerations. in IEEE Vehicular Technol Conf (2004)

9. MAM El-Bendary, A Abou El-Azm, N El-Fishwy, MAR El-Tokhy, FE Abd ElSamie, H Kazimian, F Shawki, An efficient chaotic interleaver for image transmission over IEEE 802.15.4 Zigbee network. J Telecommun Inf Technol. 2, 67-73 (2011)

10. L-J Chen, T Sun, Y-C Chen, Improving Bluetooth throughput using FEC and interleaving. in International Conference on Mobile Ad Hoc sensor Networks, Hong Kong 726-736 (2006)

11. MAM Mohamed, A Abou El-Azm, N El-Fishwy, MAR El-Tokhy, FE Abd ElSamie, F Shawki, Bluetooth performance improvement with existing convolutional codes over AWGN channel, in 2nd International Conference on Electrical Engineering Design and Technologies (ICEEDT'08) Transaction No. 537. Hammamet, Tunisia, (8-10 November 2008)

12. N Golmie, RE Van Dck, A Soltanian, Interference of Bluetooth and IEEE 802.11: simulation modeling and performance evaluation. in Proceedings ACM Int. Workshop on Modeling, Analysis, and Simulation of Wireless and Mobile Systems, Italy (2001)

13. S Vafi, T Wysocki, Performance of convolutional interleavers with different spacing parameters in turbo codes. in Proc. 6th Australian Workshop on Communications Theory 8-12 (2005)

14. W Lu, H Tao, F Chung, Chaos-based spread spectrum robust watermarking in DWT domain. in Fourth International Conference on Machine Learning and Cybernetics, Guangzhou (18-21 August 2005)

15. FE Abd El-Samie, ES Hassan, X Zhu, SE El-Khamy, MI Dessouky, SA El-Dolil, A chaotic interleaving scheme for the continuous phase modulation based single-carrier frequency-domain equalization system. Wirel Pers Commun. 62(1), 183-199. Published online 11 June 2010

16. B Jovic, C Unsworth, Chaos-based multi-user time division multiplexing communication system. Commun IET. 1(4), 549-555 (2007). doi:10.1049/ietcom:20060672

17. R Matthews, On the derivation of a chaotic encryption algorithm. Cryptologia. XIII(1), 29-42 (1989)

18. KS Deffeyes, Encryption system and method. US Patent no. 5001754 (March 1991)

19. J Fridrich, Symmetric ciphers based on two-dimensional chaotic maps. Int J Bifurcat Chaos. 8, 1259-1284 (1998). doi:10.1142/S021812749800098X

20. J Fridrich, Image encryption based on chaotic maps. in Proc IEEE Int Conf Syst Man Cybern 1105-1110 (1997)

21. Q Qian, Z Chen, Z Yuan, Video compression and encryption based-on multiple chaotic system. in Proceedings of The 3rd International Conference on Innovative Computing Information and Control (ICICIC'O8)

22. TY Chui, F Thaler, WG Scanlon, A novel channel modeling technique for performance analysis of Bluetooth baseband packets. in Proceedings of the IEEE ICC Conference New York (2002) 
23. JC Haartsen, S Zürbes, Bluetooth voice and data performance in 802.11 DS WLAN environment. Ericsson Report (1999)

24. Alpha Concept Group, Wideband Direct Sequence CDMA (WCDMA) Evaluation Document (3.0). Tdoc SMG 905/97, Madrid, Spain (15-19 December 1997)

25. A Conti, D Dardari, G Paolini, O Andrisano, Bluetooth and IEEE 802.11b coexistence: analytical performance evaluation in fading channels. IEEE Trans Sel Areas Commun. 21(2), 259-269 (2003). doi:10.1109/ JSAC.2002.807345

26. WC Jakes, Microwave Mobile Communications, (John Wiley \& Sons, Inc., New York, 1975). ISBN 0-471-43720-4

27. J Aldrich, Correlations genuine and spurious in Pearson and Yule. Stat Sci. 10, 364-376 (1995). http://www.jstor.org/stable/2246135

28. A Zanella, M Zorzi, Throughput and energy efficiency of bluetooth v2 + EDR in fading channels. in IEEE Communications Society Subject Matter Experts for Publication in the WCNC 2008 Proceedings

doi:10.1186/1687-4722-2012-4

Cite this article as: Mohamed El-Bendary et al:: Performance of the audio signals transmission over wireless networks with the channel interleaving considerations. EURASIP Journal on Audio, Speech, and Music Processing 2012 2012:4.

\section{Submit your manuscript to a SpringerOpen ${ }^{\mathcal{O}}$ journal and benefit from:}

- Convenient online submission

- Rigorous peer review

- Immediate publication on acceptance

- Open access: articles freely available online

- High visibility within the field

- Retaining the copyright to your article

Submit your next manuscript at $\gg$ springeropen.com 